\title{
The Bidirectional Relationship between Diabetes and Depression: A Literature Review
}

\author{
Abdallah Alzoubi 1**, Rnad Abunaser', Adi Khassawneh², Mahmoud Alfaqih ${ }^{3}$, Aws Khasawneh" ${ }^{4}$ Nour Abdo ${ }^{2}$ \\ 'Department of Pharmacology, Faculty of Medicine, Jordan University of Science and Technology, Irbid, Jordan \\ ${ }^{2}$ Department of Public Health and Community Medicine, Faculty of Medicine, Jordan University of Science and Technology, Irbid, Jordan \\ ${ }^{3}$ Department of Physiology and Biochemistry, Faculty of Medicine, Jordan University of Science and Technology, Irbid, Jordan \\ ${ }^{4}$ Department of Neurosciences, Faculty of Medicine, Jordan University of Science and Technology, Irbid, Jordan
}

Diabetes is a major public health problem worldwide. Depression is a serious mental condition that decreases mental and physical functioning and reduces the quality of life. Several lines of evidence suggest a bidirectional relationship between diabetes and depression: diabetes patients are twice as likely to experience depression than nondiabetic individuals. In contrast, depression increases the risk of diabetes and interferes with its daily self-management. Diabetes patients with depression have poor glycemic control, reduced quality of life, and an increased risk of diabetes complications, consequently having an increased mortality rate. Conflicting evidence exists on the potential role of factors that may account for or modulate the relationship between diabetes and depression. Therefore, this review aims to highlight the most notable body of literature that dissects the various facets of the bidirectional relationship between diabetes and depression. A focused discussion of the proposed mechanisms underlying this relationship is also provided. We systematically reviewed the relevant literature in the PubMed database, using the keywords "Diabetes AND Depression". After exclusion of duplicate and irrelevant material, literature eligible for inclusion in this review was based on meta-analysis studies, clinical trials with large sample sizes (n $\geq 1,000$ ), randomized clinical trials, and comprehensive national and cross-country clinical studies. The evidence we present in this review supports the pressing need for long, outcome-oriented, randomized clinical trials to determine whether the identification and treatment of patients with these comorbid conditions will improve their medical outcomes and quality of life.

Keywords: Bidirectional; Depression; Diabetes Mellitus; Relationship

Received: October 31, 2017, Revised: December 14, 2017, Accepted: December 21, 2017

${ }^{*}$ Corresponding Author: Abdallah Alzoubi https://orcid.org/0000-0002-0467-8420

Tel: +962-2-720-1000 (ext., 23866), Fax: +962-(0)-2-7095123, E-mail: aaalzoubi28@just.edu.jo 


\section{INTRODUCTION}

The global prevalence of diabetes has increased from $4.7 \%$ in 1980 to 8.5\% in 2014. ${ }^{1)}$ According to estimates by the International Diabetes Federation, 415 million adults have been diagnosed with diabetes mellitus (DM) worldwide, with a prevalence reaching as high as $8.8 \%$ in 2015. Approximately $75 \%$ of these individuals live in low- and middle-income countries where the increase in the number of cases is even higher than the global rate. According to the Non-Communicable Disease Collaboration, in 2016, the highest national prevalence rates were registered in the Oceania region, the Middle East, and North Africa. ${ }^{1)}$ This increase was even faster in low- and middle-income countries compared to the global rate. According to the Non-communicable Disease Collaboration, in 2016, the highest national prevalence rates were registered in the Oceania region, the Middle East, and North Africa. ${ }^{1)}$ Most diabetes patients fall into one of two broad categories: type 1 diabetes mellitus (T1DM) or type 2 diabetes mellitus (T2DM), with T2DM being the most prevalent. Due to the high prevalence of mental disorders among diabetes patients, particularly those with $\mathrm{T} 2 \mathrm{DM},{ }^{2)}$ the American Diabetes Association guidelines of 2016 recommended that diabetes patients should routinely be screened for mental health problems such as depression, diabetes-related distress, anxiety, eating disorders, and cognitive impairment.

In 2017, the World Health Organization estimated that 350 million people worldwide were affected by depression, a common mood disorder. The hallmark of major depressive disorders (MDD), as stated in "the diagnostic and statistical manual (DSM) of mental disorders (fifth edition)" is the presence of persistent loss of interest or pleasure in activities that the individual normally enjoys, sadness, and despair accompanied by an inability to carry out daily activities, for at least 2 weeks. ${ }^{3)}$ Depending on the severity of the symptoms, depression can be mild, moderate, or severe.
Several lines of evidence suggest a bidirectional relationship between diabetes and depression. Indeed, a diagnosis with diabetes mellitus increases the risk of depression. In contrast, depression is a well-established risk factor for diabetes in nondiabetic individuals, and it accelerates the occurrence of complications and contributes to poor glycemic control in diabetes patients. In the following sections, we attempt to dissect the different facets of this relationship using evidence from the relevant literature that either supports or refutes depression as a comorbid condition.

\section{PREVALENCE AND RISK OF DEPRESSION AMONG DIABETES PATIENTS}

A careful review of the literature reveals a wide variation in estimates of depression prevalence among diabetes patients, depending on the studied diabetes type, patients' age and sex, methods of depression assessment, geographical location, and study design (Tables 1, 2). After reviewing 20 relevant studies, Gavard et al. ${ }^{4)}$ in 1993 estimated the prevalence of depression to be at least three times higher among diabetes patients than among the US general adult population. Anderson et al. ${ }^{5)}$ in 2001 reviewed 39 studies with a sample size of 20,218 subjects to determine the prevalence and odds of depression in those with and without diabetes. In the studies that had a nondiabetic control group, the combined odds of depression in the diabetes group were twice that of the nondiabetic group (odds ratio [OR], 2.0; 95\% confidence interval $[\mathrm{CI}], 1.8-2.2 ; \mathrm{P}<0.0001)$. Diagnosis with MDD was evident in $11.4 \%$ of diabetes patients, while $31 \%$ reported the occurrence of depressive symptoms. Diabetic women had a higher prevalence of depressive symptoms than diabetic men (28\% versus $18 \%$; OR, 1.6 ; $95 \%$ CI, 1.4-1.8; $\mathrm{P}<0.0001)$. Moreover, the meta-analysis by Ali et al. ${ }^{6)}$ in 2006 suggested that one in six people with T2DM are likely to experience depression. The prevalence of depression in their study was sig-

Table 1. Meta-analysis studies reporting the prevalence of depression in diabetes patients

\begin{tabular}{|c|c|c|c|c|c|}
\hline $\begin{array}{l}\text { Meta-analysis } \\
\text { study }\end{array}$ & $\begin{array}{l}\text { Included study } \\
\text { design }\end{array}$ & $\begin{array}{l}\text { Diabetes } \\
\text { type }\end{array}$ & $\begin{array}{l}\text { Method of depression } \\
\text { assessment (no.) }\end{array}$ & Sample source (no.) & Prevalence \\
\hline $\begin{array}{l}\text { Gavard et al. } \\
(1993)^{4)}\end{array}$ & $\begin{array}{l}20 \text { Studies: } 9 \\
\text { controlled, } 11 \\
\text { uncontrolled }\end{array}$ & Both & $\begin{array}{l}\text { Structured diagnostic } \\
\text { interviews (9), depression } \\
\text { symptom scales (11) }\end{array}$ & $\begin{array}{l}\text { Community (5), clinics (11), } \\
\text { hospital (3), clinics+hospital } \\
\text { (1) }\end{array}$ & $\begin{array}{l}\text { Structured diagnostic interviews: controlled studies, } \\
\text { 8.5\%-27.3\% (mean, 14.0\%); uncontrolled studies, } \\
\text { 11.0\%-19.9\% (mean, 15.4\%) } \\
\text { Depression symptom scales: controlled studies, } \\
\text { 21.8\%-60.0\% (mean, 32.4\%); uncontrolled } \\
\text { studies, 10.0\%-28.0\% (mean, 19.6\%) }\end{array}$ \\
\hline $\begin{array}{l}\text { Anderson et al. } \\
(2001)^{5)}\end{array}$ & $\begin{array}{l}42 \text { Studies: } 20 \\
\text { controlled, } 22 \\
\text { uncontrolled }\end{array}$ & Both & $\begin{array}{l}\text { Structured diagnostic } \\
\text { interviews (14), depression } \\
\text { symptom scales (27), } \\
\text { both (1) }\end{array}$ & $\begin{array}{l}\text { Community (14), clinic or } \\
\text { hospital (27), unspecified } \\
\text { setting (1) }\end{array}$ & $\begin{array}{l}\text { All studies, 25.3\%; T1DM, 21.3\%; T2DM, 27.0\%; } \\
\text { controlled studies, 21\%; uncontrolled studies, } \\
\text { 30\%; diabetic women, 28.2\%; diabetic men, } \\
\text { 18.0\%; clinical samples, 31.7\%; community } \\
\text { samples, 20.1\%; self-report questionnaires, } \\
\text { 31.0\%; standardized diagnostic interviews, } 11.4 \%\end{array}$ \\
\hline Ali et al. $(2006)^{6)}$ & $\begin{array}{l}10 \text { Controlled } \\
\text { studies }\end{array}$ & T2DM & $\begin{array}{l}\text { Structured diagnostic } \\
\text { interviews (3), patient } \\
\text { notes (1), depression } \\
\text { symptom scales (6) }\end{array}$ & $\begin{array}{l}\text { Primary care (2), secondary } \\
\text { care (1), community (7) }\end{array}$ & $\begin{array}{l}\text { 17.6\%; no difference between different methods of } \\
\text { depression assessment or different sample sources }\end{array}$ \\
\hline
\end{tabular}

Controlled studies have a nondiabetic control group in addition to the diabetic group. Uncontrolled studies do not have a nondiabetic control group.

T1DM, type 1 diabetes mellitus; T2DM, type 2 diabetes mellitus. 

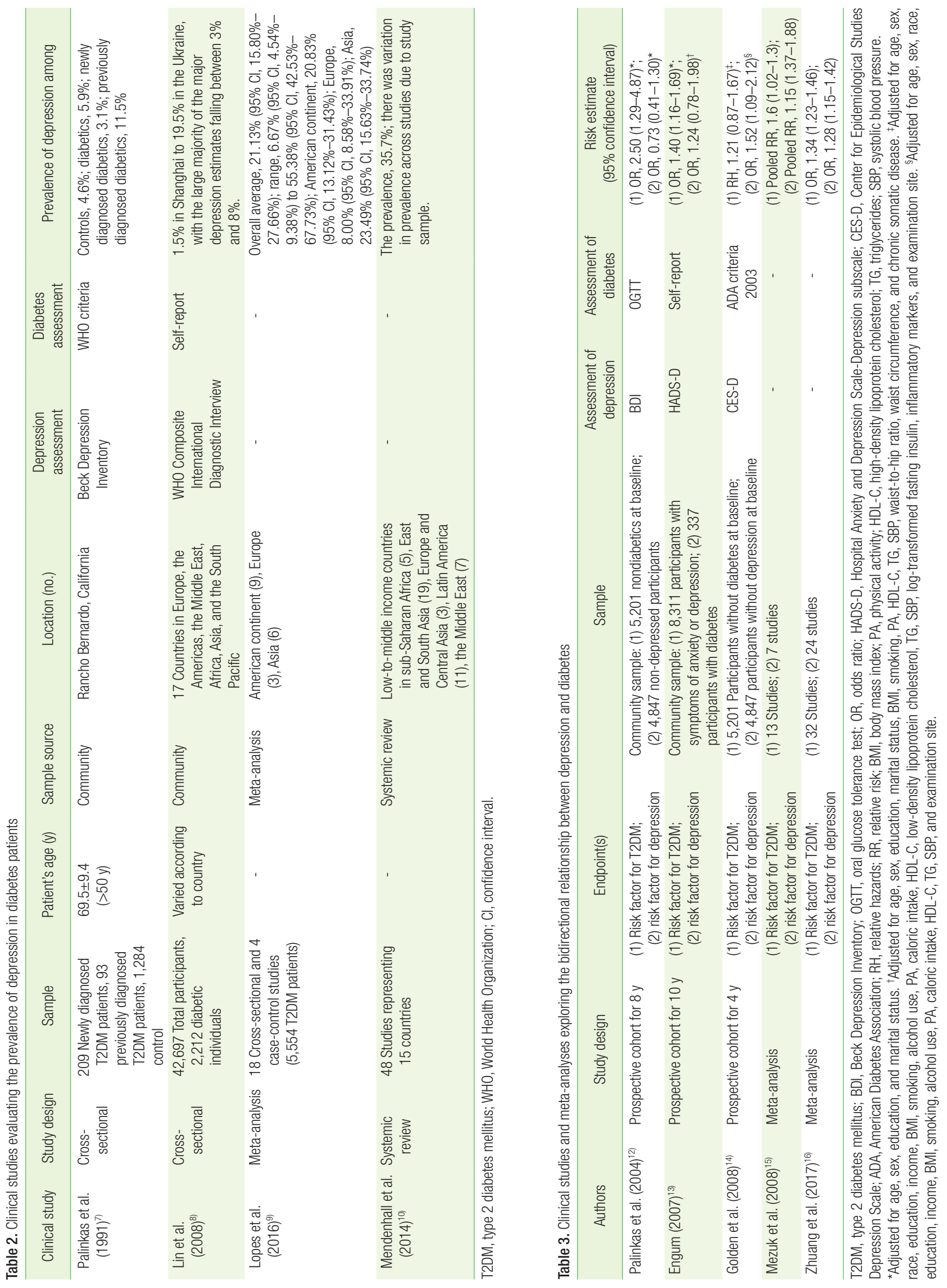
nificantly higher among T2DM patients than among nondiabetic individuals ( $17.6 \%$ versus $9.8 \%, \mathrm{P}<0.0001$ ).

Several studies differentiated between the prevalence of depression among previously diagnosed and newly diagnosed T2DM patients. Palinkas et al. ${ }^{7)}$ in 1991 reported that individuals with previously diagnosed diabetes experienced a significantly higher prevalence of depressive symptoms than those with newly diagnosed diabetes $(11.5 \%$ versus $3.1 \%, \mathrm{P}<0.05)$. The higher prevalence of depression may be explained by the psychosocial stress and poor physical health associated with the increasing duration of T2DM and the disease label.

Notably, the prevalence of depression among diabetes patients is not influenced by geographic location. Although Lin et al. ${ }^{8)}$ in 2008 agreed with the finding that the risk of depression was slightly higher among diabetes patients than among patients without diabetes (ageand sex-adjusted OR, 1.38; 95\% CI, 1.15-1.66), they reported that OR estimates between countries were not significantly different $(\mathrm{P}=0.54)$. This finding was supported by a recent meta-analysis of studies conducted in Europe, Asia, and the Americas by Lopes et al. ${ }^{9}$ in 2016. In this analysis, the prevalence of depression among patients with T2DM was higher than among nondiabetic individuals, independent of the geographic location (OR, 2.06; 95\% CI, 1.13-3.74; $\mathrm{P}=0.0174$ ). Contrary to the findings of the previous two studies, Mendenhall et al. ${ }^{10)}$ in 2014 reported that the prevalence of depression among diabetes patients living in low-to-middle-income countries was higher than the rates estimated previously by Anderson et al. ${ }^{5)}$ in 2001 in patients residing in high-income countries (35.7\% versus 25\%). These results support a role for socioeconomic class in the prevalence of depression among diabetes patients.

In addition to the high prevalence of depression among diabetic individuals, diabetes may act as a risk factor for the development of depression. A meta-analysis of 11 longitudinal studies found a $24 \%$ increased risk of depression among T2DM patients. ${ }^{11)}$ In this meta-analysis, diabetes did not predict incident depression in five studies, while it was associated with an increased risk of depression in three studies. While the aforementioned studies unidirectionally examined diabetes as a risk factor for depression, the remaining three studies included in the meta-analysis further evaluated depression as a risk factor for $\mathrm{T} 2 \mathrm{DM},{ }^{12-14)}$ thus highlighting the "bidirectional" nature of the relationship between the two conditions.

This reported notion of a bidirectional relationship between depression and T2DM was further supported by the findings of two additional meta-analyses. In the first meta-analysis by Mezuk et al. ${ }^{15)}$ in 2008, the pooled relative risk (RR) of 13 studies that assessed the relationship between depression and the risk of T2DM was estimated to be 1.6 (95\% CI, 1.37-1.88; $\mathrm{P}<0.001$ ), while the pooled RR of the seven studies that assessed T2DM as a risk factor for depression in the second arm was found to be 1.15 (95\% CI, 1.02-1.3; $\mathrm{P}<0.16$ ). In the second metaanalysis, Zhuang et al. ${ }^{16)}$ in 2017 found that depression patients were at a higher risk of diabetes than non-depression subjects ( $\mathrm{n}=32$ studies; OR, 1.34; 95\% CI, 1.23-1.46; $\mathrm{P}=0.0001$ ), and diabetes patients were at a higher risk of depression than nondiabetic subjects ( $\mathrm{n}=24$; OR, 1.28;
95\% CI, 1.15-1.42; $\mathrm{P}=0.0001)$. These results further reinforce the existence of a bidirectional relationship between depression and diabetes. Table 3 summarizes the most notable clinical studies and meta-analyses examining the bidirectional relationship between depression and diabetes.

\section{PREVALENCE AND RISK OF TYPE 2 DIABETES MELLITUS AMONG DEPRESSION PATIENTS}

The meta-analysis by Vancampfort et al. ${ }^{17)}$ in 2015 is distinctive for being the first and most comprehensive to investigate the prevalence of T2DM in patients with MDD. This meta-analysis included 16 previous studies on the topic and showed that the overall prevalence of T2DM in MDD patients was $8.7 \%$ (95\% CI, 7.3\%-10.2\%). In addition, patients with MDD had a higher risk of T2DM than did age- and sex-matched healthy controls (RR, 1.36; 95\% CI, 1.28-1.44; $\mathrm{P}<0.001)$ and to the general population (RR, 1.49; 95\% CI, 1.29-1.72; $\mathrm{P}<0.001$ ). A major limitation of this analysis was that the included studies lacked an accurate assessment of T2DM, as the authors relied solely on the self-reported history of the disease without performing confirmatory blood tests, leading to a predicted underestimation of the prevalence of T2DM in the studied population. It must be emphasized, however, that the body of evidence regarding the prevalence of T2DM among depression patients is limited, contrary to the extensive research performed to evaluate the prevalence of depression among T2DM patients, as discussed in the previous section.

The results of several studies listed in the above section support a role for depression in increasing the risk of diabetes. Eaton et al. ${ }^{18)}$ in 1996 were the first to confirm that MDD, but not depressive symptoms, were associated with an increased risk of T2DM, in a prospective population-based cohort (OR, 2.23; 95\% CI, 0.90-5.55; $\mathrm{P}=0.084$ ). Their work served as a template for future studies that evaluated depression as a risk factor for incident diabetes. In a subsequent meta-analysis that included nine studies, it was reported that depression patients had a $37 \%$ increased risk of diabetes compared with those who without depression or having minimal depression symptoms (RR, 1.37; 95\% CI, 1.14-1.63; $\mathrm{P}=0.02) .{ }^{19)}$

In a clinically significant dissection of the relationship between depression and diabetes, Schmitz et al. ${ }^{20)}$ in 2016 studied T2DM as a consequence of a cluster of medical conditions known as the metabolic syndrome. The interactions between depressive symptoms and metabolic dysregulation as risk factors for T2DM over 4.5 years was evaluated in a prospective community study of 2,525 individuals aged 40-69 years without T2DM at baseline. ${ }^{20)}$ In this study, participants who had depressive symptoms and metabolic dysregulation had the highest risk of diabetes (adjusted OR, 6.61; 95\% CI, 4.86-9.01), followed by those with metabolic dysregulations only (adjusted OR, 4.40; 95\% CI, 3.42-5.67). Depressive symptoms were not significantly associated with the risk of T2DM after adjustment for other risk factors. The combined effect of depressive symptoms and metabolic dysregulation was greater than the individual condition alone, as suggested by the syner- 
gy index (1.52; 95\% CI, 1.07-2.17). ${ }^{20)}$ Moreover, another study examined the effects of metabolic syndrome and its components on the resolution of depressive symptoms over a follow-up period of 5 years. ${ }^{21)}$ The authors reported that the delayed resolution of depressive symptoms at follow-up was only significantly associated with low levels of high-density lipoprotein cholesterol (RR, 0.82; 95\% CI, 0.68-1.00; $\mathrm{P}=0.045$ ) or high levels of triglycerides (RR, 0.81; 95\% CI, 0.70-0.95; $\mathrm{P}=0.007)$.

\section{DEPRESSION AS A MODULATOR OF GLYCEMIC CONTROL}

In addition to the potential role of MDD in increasing the risk of diabetes, several studies have found that depression in patients already diagnosed with diabetes may contribute to poor glycemic control. In a meta-analysis of 24 studies, Lustman et al. ${ }^{22}$ in 2000 found a significant association between depression and hyperglycemia in patients with T1DM and T2DM $(\mathrm{P}<0.0001)$. The association was stronger when standardized interviews and diagnostic criteria were used to assess depression, compared to self-report questionnaires. This finding was supported by the work of Richardson et al. ${ }^{23)}$ in 2008, where they examined the longitudinal effects of depression on glycemic control in 11,525 veterans with T2DM. Diabetes veterans with depression had significantly higher mean hemoglobin Alc (HbAlc) levels than diabetes patients without depression at all time points during a mean follow-up period of 4.1 years $(\mathrm{P}=0.008)$. The study by Aikens et $\mathrm{al}^{24)}$ in 2009 failed to find an association between depressive symptoms and glycemic control evaluated by $\mathrm{HbAlc}$, whether as a predictor $(\mathrm{P}=0.036)$ or as an outcome $(\mathrm{P}=0.55)$. Notably, Fisher et al. ${ }^{25)}$ in 2010 showed a lack of association between clinical depression and HbAlc levels among T2DM patients, although there was a significant association between glycemic control and diabetes-related distress, as evaluated by a self-reported questionnaire $(\mathrm{P}=0.006)$.

The exact reason why depression contributes to poor glycemic control is not entirely understood. However, it may be related to the effect depression has on self-care behaviors of diabetes patients. A significant negative association between depression and poor adherence to a healthy diet, physical activity, and medications was observed in the cross-sectional study by Lin et al. ${ }^{26)}$ in 2004, and the meta-analysis by Gonzalez et al. ${ }^{27)}$ in 2008. In contrast, the same studies reported that compliance with maintaining preventive services for diabetes, such as foot care and screening for diabetic complications, was not significantly different between patients with and without depression. ${ }^{26,27)}$

\section{DEPRESSION AS A CONTRIBUTOR TO, AND AN ACCELERATOR OF, DIABETES COMPLICATIONS}

Substantial evidence suggests that depression could act as a contributor to, and an accelerator of, the complications of diabetes. A longitudinal study on a cohort of 4,623 primary care T2DM patients followed for 5 years found a significant association between major depression and adverse microvascular (hazard ratio [HR], 1.36; 95\% CI, 1.05-1.75) and macrovascular complications (HR, 1.24; 95\% CI, 1.0-1.54) after adjustment for prior complications and demographic, clinical, and diabetes self-care variables. ${ }^{28)}$ These findings were in line with the results of a previous meta-analysis by de Groot et al. ${ }^{29)}$ in 2001, where they reported a significant association between depression and each of the microvascular (e.g., retinopathy, nephropathy, and neuropathy) and macrovascular diabetic complications, although the strength of the association was small to moderate.

\section{DEPRESSION AND RISK OF MORTALITY IN DIABETES PATIENTS}

The contribution of depression to poor glycemic control and increased diabetic complications suggests that depression may also be involved in increasing the mortality from diabetes. A meta-analysis of 16 studies revealed a significant $46 \%$ increase in the risk of all-cause mortality among diabetes patients with depression compared with those without depression. Based on the findings of five other studies, the same meta-analysis reported a significant $39 \%$ increase in the risk of cardiovascular mortality among diabetes patients with depression. ${ }^{30)}$ Furthermore, Coleman et al. ${ }^{31)}$ in 2013 found that depression status was significantly associated with both non-cardiovascular, non-cancer mortality (HR, 1.61; 95\% CI, 1.17-2.22; $\mathrm{P}<0.05$ ) and all-cause mortality (HR, 1.52; 95\% CI, 1.25-1.85; $\mathrm{P}<0.05$ ), while it was not significantly associated with either cardiovascular mortality (HR, 1.27; 95\% CI, 0.901.78; $\mathrm{P}>0.05$ ) or cancer-related mortality (HR, 1.0; 95\% CI, 0.65-1.53; $\mathrm{P}>0.05$ ). Zhang et al. $\left.{ }^{32}\right)$ in 2005 examined the difference in mortality risk between diabetic individuals with or without depression, and between individuals with and without diabetes at baseline. Mortality risk was significantly elevated among diabetic individuals who also had moderate depressive symptoms (HR, 1.63; 95\% CI, 1.10-2.42; $\mathrm{P}<0.001$ ) or severe depressive symptoms (HR, 1.49; 95\% CI, 1.04-2.12; $\mathrm{P}<0.001$ ). However, mortality risk was not statistically related to the presence of depression among nondiabetic individuals. ${ }^{32)}$

\section{EFFECT OF TREATMENT ON RELATIONSHIP BETWEEN DEPRESSION AND DIABETES}

Based on the above discussion, it can be concluded that depression may negatively affect glycemic control, increase the risk of diabetes complications, and increase the mortality rates among diabetes patients. Accordingly, an effective treatment for depression in this population is warranted, not only to improve depressive symptoms and the quality of life but also to indirectly improve diabetes treatment outcomes and to reduce illness burden. A careful review of the relevant literature showed that three types of depression interventions were extensively discussed in this area: psychosocial, pharmacological, and collaborative care.

One meta-analysis, that included only randomized controlled trials (RCTs), of the effectiveness of cognitive behavioral therapy (CBT) in- 
terventions on glycemic control among adults with diabetes found a significant reduction in mean HbAlc levels in the CBT group when compared with control groups after treatment for 4 or 8 months $\left(\mathrm{P}=0.07\right.$ and 0.0001 , respectively) ${ }^{33)}$ Similarly, CBT significantly improved the severity of depression in adults with depression and diabetes after treatment for 4,8 , and 12 months $(\mathrm{P}=0.0001,0.02$, and 0.001 , respectively). However, the effect of CBT on HbAlc was lost after 12 months $(\mathrm{P}=0.18)$, despite appropriate booster $\mathrm{CBT}$ sessions. ${ }^{33)}$ This effect may be explained by the fact that the CBT interventions were too short to generate lasting effects or were not customized to the specific needs of diabetes patients. A firm conclusion about the long-term outcomes of CBT cannot be made due to the small number of studies that examined it, encouraging further well-designed RCTs.

The effect of pharmacotherapy on the outcomes of diabetes was first reported by Turkington ${ }^{34)}$ in 1980, suggesting that imipramine or amitriptyline relieved both depression and diabetic neuropathy of the lower extremities in diabetes patients with depression. Using this study as a template, the effect of different types and classes of antidepressants on both diseases was further studied. Overall, depressive symptoms were significantly improved in the groups receiving pharmacotherapy than in the placebo group; however, the effect on glycemic control varied between the different types of drugs. For example, nortriptyline worsened glycemic control, as indicated by higher HbAlc levels $(\mathrm{P}=0.5)$, due to its direct hyperglycemic effect. ${ }^{35)}$ Moreover, antidepressant treatment with fluoxetine, ${ }^{36)}$ sertraline, ${ }^{37)}$ paroxetine, ${ }^{38)}$ or escitalopram $^{39)}$ resulted in non-significant reductions in HbAlc levels in the intervention group compared to the placebo group $(\mathrm{P}=0.13,0.9$, 0.08 , and 0.82 , respectively), while bupropion significantly reduced HbAlc levels through independent improvements in mood and body composition $(\mathrm{P}<0.01) .{ }^{40)}$

In addition to studying the effect of different antidepressants on the relationship between depression and diabetes, the effects of two antidiabetic agents, pioglitazone and metformin, on the outcome of depression were described in the literature. The most recent meta-analysis by Colle et al. ${ }^{41)}$ in 2016 reviewed four double-blinded RCTs that included 161 patients diagnosed with MDD to evaluate the effect of pioglitazone on depression. Pioglitazone was administered to 81 patients either alone or as add-on therapy to conventional antidepressant drugs. The remaining 80 control subjects either received a placebo or metformin. Pioglitazone achieved superior improvements in depressive symptoms (mean difference, 3.3; 95\% CI, 2.6-4.0; $\mathrm{P}<0.0001$ ) and remission rates (OR, 3.3; 95\% $\mathrm{CI}, 1.4-7.8 ; \mathrm{P}=0.008)$ than controls. Importantly, the improvement in depressive symptoms was higher in the subgroup of patients without metabolic comorbidities (OR, 5.1; 95\% CI, 1.5-17.9; $\mathrm{P}=0.01$ ). The observed association was independent of depression severity at baseline and of any concomitant medication. ${ }^{41)}$

Guo et al. ${ }^{42)}$ in 2014 assessed the effect of metformin on the outcome of depression in a randomized placebo-controlled study of 58 patients with comorbid depression and T2DM. After 24 weeks, metformin improved the cognitive performance of study subjects when compared to the placebo group $(\mathrm{P}<0.001)$. The authors additionally reported that depressive symptoms were improved compared to the baseline $(\mathrm{P}<0.001)$. In the intervention group, depressive symptoms were associated with $\mathrm{HbAlc}$ levels $(\mathrm{r}=0.618, \mathrm{P}<0.01)$. However, the inclusion of only mild- to moderately depression patients may have limited the results of this study, as the biased exclusion of patients with severe depression harbors the risk of overestimating the effects of metformin treatment. $^{42)}$

\section{PROPOSED MECHANISMS UNDERLYING THE RELATIONSHIP BETWEEN DEPRESSION AND DIABETES}

A number of mechanisms have been suggested to explain the link between diabetes and depression. These mechanisms include shared inflammatory pathways, dysfunction of the hypothalamic-pituitary-adrenal (HPA) axis, common metabolic effectors like leptin, in addition to a host of environmental, genetic, and behavioral factors.

\section{Inflammation}

A growing body of evidence indicates that inflammation is a key shared factor in the bidirectional relationship between depression and T2DM and it has been implicated in the development of both diseases. The meta-analysis by Haapakoski et al. ${ }^{43)}$ in 2015, which included 58 studies, observed a significant elevation of the levels of inflammatory biomarkers, such as the C-reactive protein (CRP) and interleukin (IL)6 , in patients with MDD. Moreover, the relationship between inflammation and the risk of future depression was studied by Khandaker et al. ${ }^{44)}$ in 2014, where they found that elevated levels of IL-6, but not CRP, in childhood (at 9 years of age) increased the risk of future depression (at 18 years of age). In contrast, the role of inflammation in diabetes was extensively validated in a meta-analysis of 19 cohort and nested case-control studies, which found that elevated levels of CRP predicted the development of T2DM (RR, 1.26; 95\% CI, 1.16-1.37; P=0.000). ${ }^{45)}$

The work of Au et al ${ }^{46)}$ in 2014 stands out as a major clinical study to examine the role of inflammation in the comorbidity of depression and diabetes. The authors investigated the association between depressive symptoms and CRP levels with the T2DM incidence in a prospective cohort of 4,955 community-dwelling adults (age $\geq 50$ years). After approximately 6 years of follow-up, two observations were made. First, the HR for incident T2DM was the highest among participants with elevated depressive symptoms and high CRP levels (age- and sexadjusted HR, 4.31; 95\% CI, 2.70-6.86). Second, after adjustments for comorbidities and body mass index (BMI), the risk of incident T2DM in participants with elevated depressive symptoms and high CRP levels was attenuated; however, it remained significant (adjusted HR, 2.03; 95\% CI, 1.14-3.61). ${ }^{46)}$

Herder et al. ${ }^{47}$ in 2017 investigated the association between depressive symptoms and biomarkers of subclinical inflammation concerning the type of diabetes. These biomarkers included serum high-sensitivity CRP (hsCRP), IL-6, IL-18, the high-molecular-weight (HMW)/total adiponectin ratio, and soluble intercellular adhesion molecule-1 
(sICAM-1). The severity of depressive symptoms was found to be positively associated with hsCRP and the HMW/total adiponectin ratio in T2DM patients ( $\mathrm{P}<0.01$ for both), and with sICAM-1 levels in T1DM patients $(\mathrm{P}=0.035)$. However, levels of IL-6 and IL-18 were not associated with the severity of depressive symptoms in either T1DM or T2DM patients. The findings of this study strongly indicate that general immune activation may not be linked to depressive symptoms, but rather to specific inflammatory profiles. However, the lack of a nondiabetic control group may have critically limited the practical implications of these findings. ${ }^{47)}$

\section{Hypothalamic-Pituitary-Adrenal Axis}

Ample evidence exists to support the involvement of the HPA axis in the pathogenesis of both depression and diabetes. One meta-analysis found that depression was associated with dysregulation of the HPA axis, resulting in higher cortisol and adrenocorticotropic hormone levels, and lower corticotropin-releasing hormone levels. ${ }^{48)}$ One of the key strengths of this meta-analysis was the inclusion of more than 400 studies, which effectively neutralized the fundamental sources of heterogeneity in the literature related to this concept, such as how the HPA axis was assessed, and the various participants' demographic and clinical factors. Other studies have supported the role of HPA axis dysregulation in diabetes, as diabetes patients were found to have higher levels of cortisol before and after the dexamethasone suppression test, ${ }^{49)}$ as well as a flatter diurnal cortisol curve with evidence of a blunted cortisol awakening response and a less steep slope throughout the day. ${ }^{50)}$ To the contrary, the longitudinal cohort study by Spanakis et al. ${ }^{51)}$ in 2016 reported that none of the aforementioned changes in the components of the diurnal cortisol profile were significantly different between diabetic and nondiabetic participants over a six-year period after adjustment for confounding factors like the subjects' age, sex, and use of medications that may impact HPA axis function.

In an effort to explain the relationship between cortisol levels, insulin resistance, and depression, Yokoyama et al. ${ }^{52)}$ in 2015 measured plasma cortisol levels following the dexamethasone suppression test in addition to the insulin resistance index in 15 patients with depression and 17 age- and sex-matched healthy controls. No significant difference was observed in the peak cortisol values or the insulin resistance index between the two groups. However, in patients with depression, peak cortisol values correlated significantly with the insulin resistance index following the dexamethasone suppression test $(r=0.54, \mathrm{P}<0.05)$. Despite such evidence, and to the best of our knowledge, there have been no sound clinical studies exacting the role of HPA axis dysregulation in the comorbidity of diabetes and depression. However, other studies have investigated whether HPA axis hyperactivation in depression and/or diabetes may be due to variants in the HPA axis-related genes. For instance, the systematic review by Gragnoli $^{53)}$ in 2014 identified the MC4R, NR3C1, and NR3C2 genes as risk genes in both T2DM and depression.

\section{Leptin}

Other researchers have suggested a role for leptin in the association between depression and diabetes. Leptin is a protein that is mainly produced by adipocytes and is responsible for the regulation of appetite, energy, and body fat and water composition. ${ }^{54)}$ Jow et al. ${ }^{55)}$ in 2006 found that leptin levels were significantly lower in patients with MDD than in healthy controls $(\mathrm{P}<0.05)$, and were negatively correlated with the severity of depression $(\mathrm{r}=-0.067, \mathrm{P}<0.05)$. Moreover, Chirinos et al. ${ }^{56)}$ in 2013 studied the association between circulating leptin levels and depressive symptoms in 135 patients with metabolic syndrome. Leptin was significantly associated with somatic depressive symptoms $(\mathrm{P}=0.023)$ in patients with metabolic syndrome, after controlling for age, sex, insulin resistance, BMI, and inflammation. ${ }^{56)}$ Similarly, the role of leptin in diabetes was supported by a meta-analysis of 11 prospective studies by Chen et al. ${ }^{57)}$ in 2014 . The authors reported a significant association between leptin and an increased risk of T2DM in a sex-specific manner, where elevated leptin levels were related to an increased risk of T2DM in men (RR, 1.37; 95\% CI, 1.13-1.66; $\mathrm{P}=0.003$ ), but not in women (RR, 0.96; 95\% CI, 0.90-1.03; $\mathrm{P}=0.24) .{ }^{57}$ )

To investigate the role of leptin in depression associated with diabetes, levels of leptin were recently measured by Haleem et al. ${ }^{58)}$ in 2017 in different BMI groups of diabetes patients with and without depression and were compared with the levels in age-matched healthy normal-weight volunteers. The study found a weight-dependent increase in leptin levels in diabetes patients with and without depression. In normal-weight diabetes patients, leptin levels were significantly lower in the depression group than in the non-depression group $(\mathrm{P}<0.05$ in men and $\mathrm{P}<0.01$ in women). In contrast, leptin levels were higher in obese men with diabetes and concomitant depression than in their non-depression counterparts $(\mathrm{P}<0.01)$. Moreover, leptin levels were higher in men with diabetes than in those without diabetes $(\mathrm{P}<0.01)$. Notably, none of the differences were significant in women. ${ }^{58)}$

\section{Genetic Factors}

Several studies have attempted to explain the relationship between depression and diabetes through the presence of a common genetic variant that predisposes individuals to both conditions. For example, 20 single-nucleotide polymorphisms (SNPs) previously reported to be linked with the risk of T2DM were tested for their association, independently or in combination, with T2DM or MDD in a cross-sectional cohort of 17,404 individuals. ${ }^{59)}$ Individuals who were enrolled in this study had a baseline assessment of their T2DM status using the oral glucose tolerance test and were diagnosed with major depression according to the DSM 4 diagnostic criteria. The study found that although 12 out of the 20 SNPs and the combined genotyping score were associated with T2DM (adjusted $\mathrm{P}<0.048$ ), none of the SNPs were associated with MDD as evaluated by the DSM 4 diagnostic criteria (adjusted $\mathrm{P} \geq 0.09$ ). Furthermore, the study found no association between T2DM and depression at the phenotypic level (adjusted $\mathrm{P} \leq 0.65$ ). Clarke et al. ${ }^{60)}$ in 2017 used Mendelian randomization in a populationbased cohort of 21,516 individuals to test the association between 
MDD and 11 SNPs previously found to be associated with T2DM. In their analysis, only the A allele of rs6808574 was negatively associated with MDD. Based on the results of the aforementioned studies, it is difficult to establish a genetic basis for the relationship between T2DM and MDD.

\section{CONCLUSION}

Despite the complex and conflicting nature of the available body of evidence, a bidirectional relationship between depression and diabetes is highly possible. The present findings support the pressing need for long, outcome-oriented, randomized clinical trials to determine whether the identification and treatment of patients with these comorbid conditions will improve their medical outcomes and quality of life, and possibly have beneficial effects on both mood and glycemic control. This review also endorses the concept of integration of mental health assessment in primary health care systems, particularly in the domain of diabetes. Similarly, we recommend frequent screening for diabetes in patients with depression. This, consequently, will aid in the early detection and improved management of this chronic debilitating condition. In addition, a more precise understanding of the underlying mechanisms of this bidirectional relationship would ideally open the door for new and advanced therapeutic and preventive options for both conditions in the near future.

\section{CONFLICT OF INTEREST}

No potential conflict of interest relevant to this article was reported.

\section{ACKNOWLEDGMENTS}

This review was funded by the Deanship of Research at Jordan University of Science and Technology (grant \#232/2015).

\section{REFERENCES}

1. NCD Risk Factor Collaboration (NCD-RisC). Worldwide trends in diabetes since 1980: a pooled analysis of 751 population-based studies with 4.4 million participants. Lancet 2016;387:1513-30.

2. Osborn DP, Wright CA, Levy G, King MB, Deo R, Nazareth I. Relative risk of diabetes, dyslipidaemia, hypertension and the metabolic syndrome in people with severe mental illnesses: systematic review and metaanalysis. BMC Psychiatry 2008;8:84.

3. American Psychiatric Association, American Psychiatric Association, DSM-5 Task Force. Diagnostic and statistical manual of mental disorders: DSM-5. Arlington (VA): American Psychiatric Association; 2013.

4. Gavard JA, Lustman PJ, Clouse RE. Prevalence of depression in adults with diabetes: an epidemiological evaluation. Diabetes Care 1993;16:1167-78.

5. Anderson RJ, Freedland KE, Clouse RE, Lustman PJ. The prevalence of comorbid depression in adults with diabetes: a meta-analysis. Diabetes Care 2001;24:1069-78.
6. Ali S, Stone MA, Peters JL, Davies MJ, Khunti K. The prevalence of comorbid depression in adults with Type 2 diabetes: a systematic review and meta-analysis. Diabet Med 2006;23:1165-73.

7. Palinkas LA, Barrett-Connor E, Wingard DL. Type 2 diabetes and depressive symptoms in older adults: a population-based study. Diabet Med 1991;8:532-9.

8. Lin EH, von Korff M, Alonso J, Angermeyer MC, Anthony J, Bromet E, et al. Mental disorders among persons with diabetes: results from the World Mental Health Surveys. J Psychosom Res 2008;65:571-80.

9. Lopes A, Perry IS, Bavaresco DV, Tuon L, Ceretta LB, Simoes PW, et al. Association between major depression and type 2 diabetes mellitus: a meta-analysis and meta-regression of observational studies. Int Arch Med 2016;9:1-11. https://doi.org/10.3823/1920.

10. Mendenhall E, Norris SA, Shidhaye R, Prabhakaran D. Depression and type 2 diabetes in low- and middle-income countries: a systematic review. Diabetes Res Clin Pract 2014;103:276-85.

11. Nouwen A, Winkley K, Twisk J, Lloyd CE, Peyrot M, Ismail K, et al. Type 2 diabetes mellitus as a risk factor for the onset of depression: a systematic review and meta-analysis. Diabetologia 2010;53:2480-6.

12. Palinkas LA, Lee PP, Barrett-Connor E. A prospective study of type 2 diabetes and depressive symptoms in the elderly: the Rancho Bernardo Study. Diabet Med 2004;21:1185-91.

13. Engum A. The role of depression and anxiety in onset of diabetes in a large population-based study. J Psychosom Res 2007;62:31-8.

14. Golden SH, Lazo M, Carnethon M, Bertoni AG, Schreiner PJ, Diez Roux AV, et al. Examining a bidirectional association between depressive symptoms and diabetes. JAMA 2008;299:2751-9.

15. Mezuk B, Eaton WW, Albrecht S, Golden SH. Depression and type 2 diabetes over the lifespan: a meta-analysis. Diabetes Care 2008;31:2383-90.

16. Zhuang QS, Shen L, Ji HF. Quantitative assessment of the bidirectional relationships between diabetes and depression. Oncotarget 2017;8:23389-400.

17. Vancampfort D, Mitchell AJ, De Hert M, Sienaert P, Probst M, Buys R, et al. Type 2 diabetes in patients with major depressive disorder: a meta-analysis of prevalence estimates and predictors. Depress Anxiety 2015;32:763-73.

18. Eaton WW, Armenian H, Gallo J, Pratt L, Ford DE. Depression and risk for onset of type II diabetes: a prospective population-based study. Diabetes Care 1996;19:1097-102.

19. Knol MJ, Twisk JW, Beekman AT, Heine RJ, Snoek FJ, Pouwer F. Depression as a risk factor for the onset of type 2 diabetes mellitus: a meta-analysis. Diabetologia 2006;49:837-45.

20. Schmitz N, Deschenes SS, Burns RJ, Smith KJ, Lesage A, Strychar I, et al. Depression and risk of type 2 diabetes: the potential role of metabolic factors. Mol Psychiatry 2016;21:1726-32.

21. Virtanen M, Ferrie JE, Akbaraly T, Tabak A, Jokela M, Ebmeier KP, et al. Metabolic syndrome and symptom resolution in depression: a 5-year follow-up of older adults. J Clin Psychiatry 2017;78:e1-e7.

22. Lustman PJ, Anderson RJ, Freedland KE, de Groot M, Carney RM, Clouse RE. Depression and poor glycemic control: a meta-analytic review of the literature. Diabetes Care 2000;23:934-42.

23. Richardson LK, Egede LE, Mueller M, Echols CL, Gebregziabher M. Longitudinal effects of depression on glycemic control in veterans with type 2 diabetes. Gen Hosp Psychiatry 2008;30:509-14. 
24. Aikens JE, Perkins DW, Lipton B, Piette JD. Longitudinal analysis of depressive symptoms and glycemic control in type 2 diabetes. Diabetes Care 2009;32:1177-81.

25. Fisher L, Mullan JT, Arean P, Glasgow RE, Hessler D, Masharani U. Diabetes distress but not clinical depression or depressive symptoms is associated with glycemic control in both cross-sectional and longitudinal analyses. Diabetes Care 2010;33:23-8.

26. Lin EH, Katon W, von Korff M, Rutter C, Simon GE, Oliver M, et al. Relationship of depression and diabetes self-care, medication adherence, and preventive care. Diabetes Care 2004;27:2154-60.

27. Gonzalez JS, Peyrot M, McCarl LA, Collins EM, Serpa L, Mimiaga MJ, et al. Depression and diabetes treatment nonadherence: a meta-analysis. Diabetes Care 2008;31:2398-403.

28. Lin EH, Rutter CM, Katon W, Heckbert SR, Ciechanowski P, Oliver $\mathrm{MM}$, et al. Depression and advanced complications of diabetes: a prospective cohort study. Diabetes Care 2010;33:264-9.

29. De Groot M, Anderson R, Freedland KE, Clouse RE, Lustman PJ. Association of depression and diabetes complications: a meta-analysis. Psychosom Med 2001;63:619-30.

30. Van Dooren FE, Nefs G, Schram MT, Verhey FR, Denollet J, Pouwer F. Depression and risk of mortality in people with diabetes mellitus: a systematic review and meta-analysis. PLoS One 2013;8:e57058.

31. Coleman SM, Katon W, Lin E, von Korff M. Depression and death in diabetes; 10-year follow-up of all-cause and cause-specific mortality in a diabetic cohort. Psychosomatics 2013;54:428-36.

32. Zhang X, Norris SL, Gregg EW, Cheng YJ, Beckles G, Kahn HS. Depressive symptoms and mortality among persons with and without diabetes. Am J Epidemiol 2005;161:652-60.

33. Uchendu C, Blake H. Effectiveness of cognitive-behavioural therapy on glycaemic control and psychological outcomes in adults with diabetes mellitus: a systematic review and meta-analysis of randomized controlled trials. Diabet Med 2017;34:328-39.

34. Turkington RW. Depression masquerading as diabetic neuropathy. JAMA 1980;243:1147-50.

35. Lustman PJ, Griffith LS, Clouse RE, Freedland KE, Eisen SA, Rubin EH, et al. Effects of nortriptyline on depression and glycemic control in diabetes: results of a double-blind, placebo-controlled trial. Psychosom Med 1997;59:241-50.

36. Lustman PJ, Freedland KE, Griffith LS, Clouse RE. Fluoxetine for depression in diabetes: a randomized double-blind placebo-controlled trial. Diabetes Care 2000;23:618-23.

37. Lustman PJ, Clouse RE, Nix BD, Freedland KE, Rubin EH, McGill JB, et al. Sertraline for prevention of depression recurrence in diabetes mellitus: a randomized, double-blind, placebo-controlled trial. Arch Gen Psychiatry 2006;63:521-9.

38. Paile-Hyvarinen M, Wahlbeck K, Eriksson JG. Quality of life and metabolic status in mildly depressed women with type 2 diabetes treated with paroxetine: a single-blind randomised placebo controlled trial. BMC Fam Pract 2003;4:7.

39. Amsterdam JD, Shults J, Rutherford N, Schwartz S. Safety and efficacy of s-citalopram in patients with co-morbid major depression and diabetes mellitus. Neuropsychobiology 2006;54:208-14.

40. Lustman PJ, Williams MM, Sayuk GS, Nix BD, Clouse RE. Factors influencing glycemic control in type 2 diabetes during acute- and maintenance-phase treatment of major depressive disorder with bupropion.
Diabetes Care 2007;30:459-66.

41. Colle R, de Larminat D, Rotenberg S, Hozer F, Hardy P, Verstuyft C, et al. Pioglitazone could induce remission in major depression: a metaanalysis. Neuropsychiatr Dis Treat 2016;13:9-16.

42. Guo M, Mi J, Jiang QM, Xu JM, Tang YY, Tian G, et al. Metformin may produce antidepressant effects through improvement of cognitive function among depressed patients with diabetes mellitus. Clin Exp Pharmacol Physiol 2014;41:650-6.

43. Haapakoski R, Mathieu J, Ebmeier KP, Alenius H, Kivimaki M. Cumulative meta-analysis of interleukins 6 and $1 \beta$, tumour necrosis factor $\alpha$ and C-reactive protein in patients with major depressive disorder. Brain Behav Immun 2015;49:206-15.

44. Khandaker GM, Pearson RM, Zammit S, Lewis G, Jones PB. Association of serum interleukin 6 and C-reactive protein in childhood with depression and psychosis in young adult life: a population-based longitudinal study. JAMA Psychiatry 2014;71:1121-8.

45. Wang X, Bao W, Liu J, Ouyang YY, Wang D, Rong S, et al. Inflammatory markers and risk of type 2 diabetes: a systematic review and metaanalysis. Diabetes Care 2013;36:166-75.

46. Au B, Smith KJ, Gariepy G, Schmitz N. C-reactive protein, depressive symptoms, and risk of diabetes: results from the English Longitudinal Study of Ageing (ELSA). J Psychosom Res 2014;77:180-6.

47. Herder C, Furstos JF, Nowotny B, Begun A, Strassburger K, Mussig K, et al. Associations between inflammation-related biomarkers and depressive symptoms in individuals with recently diagnosed type 1 and type 2 diabetes. Brain Behav Immun 2017;61:137-45.

48. Stetler C, Miller GE. Depression and hypothalamic-pituitary-adrenal activation: a quantitative summary of four decades of research. Psychosom Med 2011;73:114-26.

49. Roy M, Collier B, Roy A. Hypothalamic-pituitary-adrenal axis dysregulation among diabetic outpatients. Psychiatry Res 1990;31:31-7.

50. Bruehl H, Wolf OT, Convit A. A blunted cortisol awakening response and hippocampal atrophy in type 2 diabetes mellitus. Psychoneuroendocrinology 2009;34:815-21.

51. Spanakis EK, Wang X, Sanchez BN, Diez Roux AV, Needham BL, Wand GS, et al. Lack of significant association between type 2 diabetes mellitus with longitudinal change in diurnal salivary cortisol: the multiethnic study of atherosclerosis. Endocrine 2016;53:227-39.

52. Yokoyama K, Yamada T, Mitani H, Yamada S, Pu S, Yamanashi T, et al. Relationship between hypothalamic-pituitary-adrenal axis dysregulation and insulin resistance in elderly patients with depression. Psychiatry Res 2015;226:494-8.

53. Gragnoli C. Hypothesis of the neuroendocrine cortisol pathway gene role in the comorbidity of depression, type 2 diabetes, and metabolic syndrome. Appl Clin Genet 2014;7:43-53.

54. German J, Kim F, Schwartz GJ, Havel PJ, Rhodes CJ, Schwartz MW, et al. Hypothalamic leptin signaling regulates hepatic insulin sensitivity via a neurocircuit involving the vagus nerve. Endocrinology 2009;150:4502-11.

55. Jow GM, Yang TT, Chen CL. Leptin and cholesterol levels are low in major depressive disorder, but high in schizophrenia. J Affect Disord 2006;90:21-7.

56. Chirinos DA, Goldberg R, Gellman M, Mendez AJ, Gutt M, McCalla JR, et al. Leptin and its association with somatic depressive symptoms in patients with the metabolic syndrome. Ann Behav Med 2013;46:31-9. 
57. Chen GC, Qin LQ, Ye JK. Leptin levels and risk of type 2 diabetes: gender-specific meta-analysis. Obes Rev 2014;15:134-42.

58. Haleem DJ, Sheikh S, Fawad A, Haleem MA. Fasting leptin and glucose in normal weight, over weight and obese men and women diabetes patients with and without clinical depression. Metab Brain Dis 2017;32:757-64.

59. Samaan Z, Garasia S, Gerstein HC, Engert JC, Mohan V, Diaz R, et al.
Lack of association between type 2 diabetes and major depression: epidemiologic and genetic evidence in a multiethnic population. Transl Psychiatry 2015;5:e618.

60. Clarke TK, Obsteter J, Hall LS, Hayward C, Thomson PA, Smith BH, et al. Investigating shared aetiology between type 2 diabetes and major depressive disorder in a population based cohort. Am J Med Genet B Neuropsychiatr Genet 2017;174:227-34. 